\title{
Visual field abnormalities in multiple sclerosis
}

\author{
V H PATTERSON AND J R HERON \\ From the Department of Neurology, North Staffordshire Hospital Centre, \\ Stoke-on-Trent, Staffs.
}

SUMMARY Visual fields were examined with a tangent screen in 54 patients with multiple sclerosis (MS) or optic neuritis (ON). Visual fields were abnormal in all patients with definite MS, $94 \%$ with probable MS and $81 \%$ with possible MS. Three-quarters of the MS patients with no history of visual symptoms had abnormal fields. The commonest defect found was an arcuate scotoma. As a diagnostic test of visual pathway involvement in MS, tangent screen examination compares favourably with more sophisticated methods.

One of the unexplained features of multiple sclerosis (MS) is the predilection which the disease shows for the anterior visual pathway-the optic nerves, chiasm and tracts. Lumsden ${ }^{1}$ found evidence of demyelination at this site in 36 consecutive autopsies on unselected patients with MS and suggested that such involvement was almost a sine qua non for the pathological diagnosis of the disease.

Symptoms referable to the anterior visual pathway are by no means universal in MS, a typical attack of optic neuritis occuring in only between $27 \%$ of and $62 \%$ of MS patients according to different series. ${ }^{23}$ Some other patients have mild and often ill-remembered symptoms but many give no history whatsoever of visual disturbance. It is this discrepancy between the clinical and pathological findings which has led to the recent interest in methods of detecting subclinical visual involvement in patients suspected of having MS. Such detection, in confirming or strengthening a diagnosis of MS, aids the management of the individual patient and increases understanding of the natural history and epidemiology of the disease.

Many different properties of vision have been used to detect subclinical optic pathway disease. These include the evoked visual response (VER) to flash $^{4}$ and pattern reversal, ${ }^{5}$ perceptual latency, ${ }^{6}$ double-flash resolution, ${ }^{7}$ contrast sensitivity, ${ }^{8}$ and the Pulfrich pendulum illusion. ${ }^{9}$ However, because the equipment and expertise required to carry out these tests is not widely available, in the present study we have investigated the much simpler method of tangent examination of the visual fields as a

Address for reprint request: Dr JR Heron, North Staffordshirz Hospital Centre, Stoke-on-Trent, Staffs. ST4 7LN.

Accepted 8 November 1979 means of detecting visual pathway disease in patients with MS.

\section{Methods and subjects}

\section{Procedure}

Subjects viewed a standard two-metre-square black tangent screen at a distance of two metres. Spectacles were worn if appropriate, and the eye not being tested was lightly occluded. A white spot at the centre of the screen was used for fixation, and standard white discs at the end of a matt-black wand were used as test objects. Two pairs of 100 Watt incandescent lamps placed behind the subject provided an even screen luminance of $2.4 \mathrm{~cd} . \mathrm{m}^{-2}$, the luminance of the test object being $172 \mathrm{cd.m}{ }^{-2}$.

The examiner first outlined the blind-spot using a $5 \mathrm{~mm}$ test object. If the blind-spot could not be charted consistently the examination was abandoned. Test objects were then moved centripetally at radial intervals of $30^{\circ}$ and at a speed of about $1 \cdot 5 \% \mathrm{sec}$. Subjects were asked to say when they became aware of the test object, whether it disappeared or became hazy, and if so, at what point it reappeared clearly. If an abnormality was detected, the field was tested at radial intervals of $15^{\circ}$ in the adjacent region. The fields were examined first with a $5 \mathrm{~mm}$ test object and then with a 1 or $2 \mathrm{~mm}$ test object.

\section{Criteria of abnormality}

A scotoma was only regarded as being significant if it crossed at least two adjacent radii $15^{\circ}$ apart, if it was greater than $1^{\circ}$ in breadth, and if it could be demonstrated repeatedly. An arcuate defect was defined as an absolute or relative scotoma between $10^{\circ}$ and $25^{\circ}$ eccentricity which was arched about 
the point of fixation. Abnormal depression of the visual field was taken to be present when the isoptre for the $2 \mathrm{~mm}$ test object fell within $15^{\circ}$ of fixation. A paracentral scotoma was one within $10^{\circ}$ of the fixation point but which did not involve it.

\section{Patients}

Fifty-five consecutive patients with MS or past $\mathrm{ON}$ who were having other diagnostic visual investigations were tested in this way. One patient in whom the blind-spots could not be determined was not included in the series. Of the remaining 54 patients 41 had MS and $13 \mathrm{ON}$. The MS patients were classified as definite, probable or possible cases by the criteria of Rose et al, $^{10}$ (1976). Twelve of these patients had no history of significant visual disturbance in either eye and this group comprised one definite, six probable, and five possible cases. The 13 patients with $\mathrm{ON}$ were made up of six unilateral, five bilateral, and two recurrent cases. All patients had been free of fresh visual symptoms for at least four weeks before visual field testing. Further details are given in table 1.

Eleven eyes with corrected visual acuity of worse than 6/9 have not been included in the present series. The remaining 97 eyes were divided into three groups, as follows:

Group A. Eyes with a history of visual disturbance.

Group B. Symptomless contralateral eyes of Group A.

Group C. Symptomless eyes from patients without a history of visual disturbance.

A history of visual disturbance included episodes of visual impairment lasting more than 24 hours (for which no other obvious cause could be found), and also shorter episodes in which visual blurring was related to hot baths, exercise or emotion.

\section{Controls}

Even though tangent screen examination of the visual fields is a long-established technique, because

Table 1 Details of patients tested

\begin{tabular}{llll}
\hline Diagnosis & $\begin{array}{l}\text { Number } \\
\text { of } \\
\text { patients }\end{array}$ & $\begin{array}{l}\text { Mean age } \\
\text { yrs } \\
\text { (range) }\end{array}$ & $\begin{array}{l}\text { Mean duration } \\
\text { yrs } \\
\text { (range) }\end{array}$ \\
\hline MS-definite & 9 & $\begin{array}{l}41 \\
(27-63)\end{array}$ & $\begin{array}{l}13 \\
(5-25)\end{array}$ \\
MS-probable & 16 & $\begin{array}{l}36 \\
(23-57)\end{array}$ & $\begin{array}{l}(0.2-42) \\
2\end{array}$ \\
MS-possible & 16 & 33 & $(0.1-5)$ \\
Cptic Neuritis & 13 & $\begin{array}{l}(24-48) \\
(21-56)\end{array}$ & \begin{tabular}{l}
$(0.1-9)$ \\
\hline
\end{tabular} \\
\hline
\end{tabular}

of the slight modifications which we used such as slow movement of the test object, we examined a control group of 10 normal subjects and 10 patients with other neurological diseases. Their age range was 21-50 years with a mean age of 33 years.

\section{Results}

\section{Control Group}

No abnormal scotomata were found by the use of $5 \mathrm{~mm}$ and $1 \mathrm{~mm}$ test objects although in a few subjects angioscotomata were detected with the $1 \mathrm{~mm}$ test object; these were absolute defects of less than $1^{\circ}$ breadth found only in the radii within $30^{\circ}$ of the blind spot with which they were continuous. The isoptres for the $1 \mathrm{~mm}$ object all fell outside $15^{\circ}$ eccentricity.

\section{Patients}

Eighty of the 97 eyes $(82 \%)$ had abnormal visual fields on tangent screen examination. An arcute scotoma was the commonest defect found, being present in 61 eyes. The frequencies of the different types of field defect are shown in table 2 and examples of the abnormal fields in figures 1 and 2.

Of the eyes with a history of visual disturbance (Group A) 94\% showed abnormal fields. In Group B $75 \%$ and in Group C $67 \%$ of eyes had abnormal fields (table 3 ).

The results expressed in terms of clinical diagnosis are shown in table 4. Visual field defects were found in all the clinically definite MS patients, in $94 \%$ of

Table 2 Types of field defect present

\begin{tabular}{ll}
\hline & $\%$ of eyes with abnormal fields \\
\hline Arcuate scotoma & 76 \\
Localised depression & 14 \\
Generalised depression & 13 \\
Paracentral scotoma & 4 \\
\hline
\end{tabular}

Table 3 Number of eyes with field defects

\begin{tabular}{llll}
\hline A. Eyes with a history of visual disturbance & $94 \%$ & $(46 / 49)$ \\
B. Symptomless contralateral eyes of Group A & $75 \%$ & $(18 / 24)$ \\
C. Symptomless eyes from patients without a & & \\
& & $67 \%$ & $(16 / 24)$ \\
& history of visual disturbance & $82 \%$ & $(80 / 97)$ \\
\hline
\end{tabular}

Table 4 Patients with field defects

\begin{tabular}{lll}
\hline & \multicolumn{2}{l}{ Percentage } \\
\hline Multiple sclerosis & & \\
Definite MS & 100 & $(9 / 9)$ \\
Probable MS & 94 & $(15 / 16)$ \\
Possible MS & 81 & $(13 / 16)$ \\
MS with no history of visual symptoms & 75 & $(9 / 12)$ \\
Optic neuritis $\quad 92$ & $(12 / 13)$ \\
$\quad$ Total & 91 & $(49 / 54)$ \\
\hline
\end{tabular}




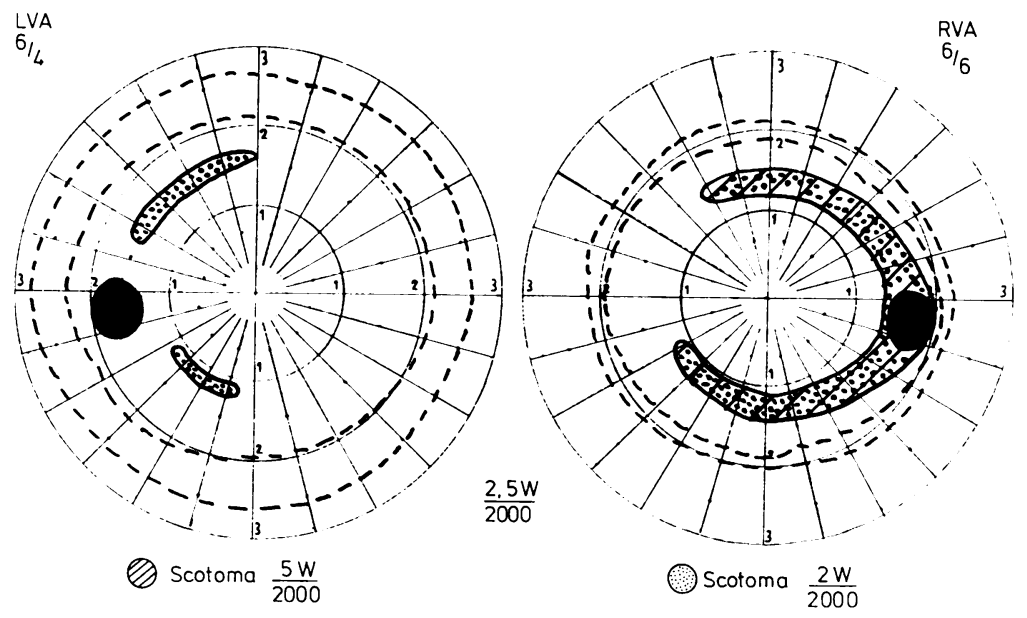

Fig 1 Visual fields from a patient with a single episode of right $O N$ three months previously showing arcuate scotomata in both eves.
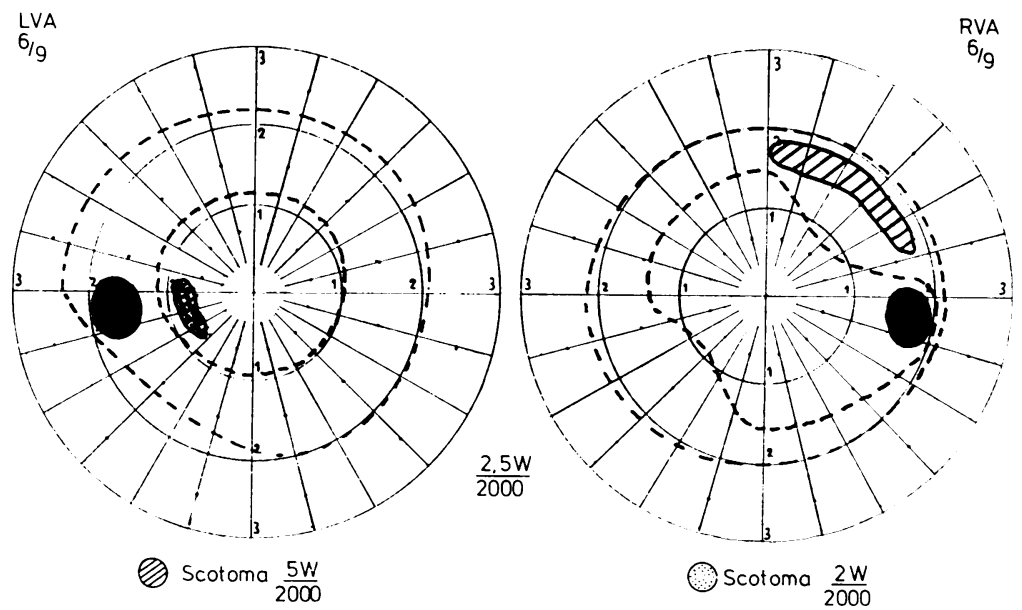

Fig 2 Visual fields from a patient with a relapsing and remitting spinal cord lesion of 10 years duration and no history of visual disturbance. The field in the right eye shows an arcuate scotoma and localised constriction of the $\frac{2 w}{2000}$ isoptre. In the left eye there is generalised constriction of this isoptre and a paracentral scotoma.

probable cases and in $81 \%$ of the possible cases. Seventy-five per cent of the MS patients without any history of visual disturbance had abnormal fields in one or both eyes; in all of these patients the abnormality found was an arcuate scotoma.

Intraocular tension was measured in 15 patients who had an arcuate scotoma and was normal in all 30 eyes.

\section{Discussion}

The results suggest that visual field defects are commonly found in patients with MS even in eyes which have never experienced symptoms. An arcuate scotoma, the commonest defect found, is produced by damage to a nerve-fibre bundle, a group of fibres which lie together as they enter the papilla. Such fibre bundles run together in the optic nerve to the chiasm where they split into crossed and uncrossed fibres. This was deduced clinically by Traquair ${ }^{11}$ and confirmed anatomically in the monkey by Hoyt. ${ }^{12}$ Such scotomata are characteristically associated with glaucoma but they may occur rarely in a number of other condtions such as pituitary tumour, optic nerve drusen and retinal artery disease. ${ }^{13}$ There was no evidence of any of these less frequent causes in our patients and the normal intraocular tensions make glaucoma unlikely.

Arcuate defects have been described in acute $\mathrm{ON}$ 1415 but reports of their occurrence in MS are conflicting. The reason for this conflict may be the method used to examine the visual fields. Ellenberger and Ziegler ${ }^{16}$ did not find any visual field defects in 25 patients with MS who had never experienced visual symptoms. They used the 
Goldmann perimeter which operates at a distance of $330 \mathrm{~mm}$ as opposed to the $2000 \mathrm{~mm}$ of the tangent screen. The narrow relative scotomata which we found using the tangent screen could easily be missed at the much shorter operating distance of the Goldmann perimeter.

When the tangent screen has been used, abnormalities in the visual field have been found. Paton ${ }^{17}$ mentioned that small relative scotomata could be demonstrated in over $50 \%$ of patients with MS whose visual acuity had returned to normal after an attack of temporary amblyopia. In Traquair's Clinical Perimetry, Scott ${ }^{18}$ refers to the occurrence in some patients of MS of "multiple small relative scotomata, paracentral or central, characterised by indistinctness, slight intensity and sloping edges...". Zeller $^{3}$ who examined the visual fields of 123 patients with MS in remission, found visual field abnormalities in $52 \%$ of eyes. Depression of the visual field was the most common abnormality and although he found a paracentral scotoma as well as depression in some fields, in none did he find a paracentral scotoma alone. We suggest that the difference between his findings and ours is due to the difference in the background illumination used. Zeller used an illumination of 4 foot-candles which is equivalent to a test object luminance of approximately $14 \mathrm{~cd} . \mathrm{m}^{-2}$ much less than our test object luminance of $172 \mathrm{~cd} . \mathrm{m}^{-2}$. The effect of reduced illumination is to depress the visual field, particularly when visual function is abnormal. Thus, the scotomata which we found between $10^{\circ}$ and $25^{\circ}$ would have been outside the depressed fields found by Zeller.

With the tangent screen, Frisen and Hoyt ${ }^{19}$ have also reported narrow relative arcuate scotomata in patients with MS. These correlated with slit defects in the nerve-fibre layer of the retina which were visible with the opthalmoscope in red-free illumination, and which the authors ascribed to axonal loss secondary to demyelination in the anterior visual pathway. However, since demyelination may block conduction without causing axonal loss, arcuate scotomata would be expected to be more prevalent than nerve-fibre layer defects.

The scotomata which we found were almost all outside the central $20^{\circ}$ of the visual field and so signify dysfunction in optic pathway fibres not accessible to tests mentioned earlier which, excepting the VER, provide information only about the central $20^{\circ}$ of vision. Tangent screen examination is therefore complementary to such tests as the pattern-reversal VER in furnishing information about the visual pathway in MS.

As a diagnostic test in its own right in patients with MS, visual field examination compares well with other methods. Measurement of VER to pattern reversal has provided variable results from different centres, using different techniques. Halliday et $a l^{5}$ consistently detected abnormalities in $100 \%$ of patients with probable MS and $92 \%$ with possible MS. Matthews et al ${ }^{19}$ reported figures of $95 \%$ and $38 \%$ respectively and those of Shahrokhi et al ${ }^{20}$ were $52 \%$ and $28 \%$. In patients with no history of visual disturbance we found abnormalities in $75 \%$ of patients compared with $93 \%$ for Halliday et al, ${ }^{5}$ and $36 \%$ for Shahtokhi et al. ${ }^{20}$ Flash VERs reported from different centres have shown a similar variation in results. Feinsod and $\mathrm{Hoyt}^{4}$ found abnormalities in $100 \%$ and Ellenberger and Ziegler ${ }^{16}$ in $64 \%$ of patients with MS and no history of visual symptoms. Our present results with the tangent screen are comparable in diagnostic terms to previous measurements of perceptual delay ${ }^{6}$ and double flash resolution in MS, the latter method being abnormal in $82 \%$ of patients without visual symptoms. ${ }^{7}$ We suggest, therefore, that visual field examination with a traditional tangent screen is a widely available, simple and sensitive method of demonstrating visual pathway damage in multiple sclerosis.

We are grateful to $\mathrm{Mr}$ WG Coddington for measuring the intraocular tensions. The work was supported by a Sheldon Clinical Research Fellowship to Dr Patterson from the West Midlands Reg:onal Health Authority.

\section{References}

1 Lumsden CE. The neuropathology of multiple sclerosis. In Handbook of Clinical Neurology Vol. 9. Eds Vinken PJ, Bruyn GW. Amsterdam, North Holland. 1970; pp 217-309.

2 Wybar, KC. (1952) The ocular manifestations of disseminated sclerosis. Proceedings of the Royal Society of Medicine 1952; 45:315-20.

3 Zeller RW. Ocular findings in the remission phase of multiple sclerosis. Americian Journal of Ophthalmology 1967; 64:767-72.

4 Feinsod M and Hoyt WF. Subclinical optic neuropathy in multiple sclerosis. Journal of Neurology, Neurosurgery and Psychiatry 1975; 38:1109-14.

5 Halliday AM McDonald WI, and Mushin J. Visual evoked response in diagnosis of multiple sclerosis. British Medical Journal 1973; 4:661-4.

6 Regan D, Milner BA, and Heron JR. Delayed visual perception and delayed visual evoked potentials in the spinal form of multiple sclerosis and in retrobulbar neuritis Brain 1976; 99:43-66.

7 Galvin RJ, Heron JR, and Regan D. Subclinical optic neuropathy in multiple sclerosis. Archives of Neurology 1977; 34:666-70.

8 Arden GB, and Gucukoglu AG. Grating test of contrast sensitivity in patients with retrobulbar neuritis. Archives of Ophthalmology 1978; 96: 1626-9. 
9 Rushton D. Use of the Pulfrich pendulum for detecting abnormal delay in the visual pathway in multiple sclerosis. Brain 1975; 98:283-96.

10 Rose AS, Ellison GW, Myers LW, and Tourtellotte WW. Criteria for the clinical diagnosis of multiple sclerosis. Neurology 1976; 26:suppl. 20-2.

11 Traquair HM. The nerve-fibre bundle defect. Transactions of the Ophthalmological Society of the United Kingdom 1944; 64:3-23.

12 Hoyt WF. Anatomic considerations of arcuate scotomas associated with lesions of the optic nerve and chiasm. A Nauta axon degeneration study in the monkey. Bulletin of the John Hopkins Hospital 1962; 3:57-71.

13 Harrington DO. Differential diagnosis of the arcuate scotoma. Investigative Ophthalmology 1969; 8:96105.

14 Chamlin M. Visual field changes in optic neuritis. Archives of Ophthalmology 1953; 50:699-713.
15 Trobe JD, Glaser JS. Quantitative perimetry in compressive optic neuropathy and optic neuritis. Archives of Ophthalmology 1978; 96:1210-16.

16 Ellenberger C, Ziegler SB. Visual evoked potentials and quantitative perimetry in multiple sclerosis. Annals of Neurology 1977; 1:561-4.

17 Paton L. Eye symptoms in disseminated sclerosis. Transactions of the Opthalmological Society of the United Kingdom 1924; 44:137.

18 Scott GI. Traquairs Clinical Perimetry 1957. London: Kimpton.

19 Matthews WB, Small DG, Small M, Pountney E. Pattern reversal evoked visual potentials in the diagnosis of multiple sclerosis. Journal of Neurology, Neurosurgery, and Psychiatry 1977; 40:1009-14.

20 Shahrokhi F, Chiappa KH, Young RR. Pattern shift visual evoked responses. Archives of Neurology 1978; 35:65-71. 